\title{
El misterio del jaguar reticulado
}

\section{The Mystery of the Reticulated Jaguar}

\author{
HeIKe Rosas-MülLer \\ Albert-Ludwigs-Universität \\ Friburgo, Alemania
}

\begin{abstract}
RESUMEN: En la iconografía mesoamericana es predominante la prodigiosa presencia de una bestia fantástica: el jaguar. El jaguar reticulado teotihuacano es una variedad de la especie que se caracteriza por un cuerpo constituido mediante una sinuosa red de diseños entrelazados y por un semblante que mira de frente, conformado, a su vez, por dos perfiles zoomorfos encontrados. Gracias al análisis iconográfico es posible precisar que estos perfiles corresponden a dos serpientes, de acuerdo con un recurso canónico mesoamericano que tuvo su origen en el periodo preclásico olmeca. A pesar de su aspecto zoomorfo, el misterioso ícono realmente simboliza el mítico momento inaugural del cosmos, siendo su rugido virtual una metáfora del Verbo creador: el trueno que estalla sobre el océano prístino entre dos serpientes de luz compuestas por un rayo y su reflejo en el agua - red luminosa de prístinas luces que los pintores mesoamericanos representaron en la forma de ondulaciones entrelazadas.
\end{abstract}

ABSTRACT: Mesoamerican iconography is dominated by the prodigious presence of a fantastic beast: the jaguar. The Teotihuacan reticulated jaguar is characterized by a sinuous network of interlaced designs covering the whole body, and by a face made up of two zoomorphic profiles facing each other. Iconographic analysis allows us to specify that these profiles correspond to two snakes, according to a Mesoamerican canonical resource originating in the Olmec Pre-classic period. Despite its zoomorphic aspect, the mysterious icon actually symbolizes the mythical opening moment of the Cosmos, and its virtual roar is a metaphor of the Word as creator: thunder bursting upon the pristine ocean between two snakes of light, composed by a lightning bolt and its reflection on the water - a luminous network of pristine lights that the Mesoamerican painters represented as intertwined undulations.

PALABRAS ClAVE: ícono del jaguar reticulado, dragón serpiente-jaguar, lenguaje plástico, metáfora, espejo de agua.

KEYWORDS: icon of reticulated jaguar, plastic language, metaphor, water mirror.

RECIBIDO: 26 de abril de 2017 - ACEPTADO: 23 de junio de 2017 



\section{HeIKe Rosas-MÜLleR}

\section{El misterio del jaguar reticulado}

Una montaña podía ser la palabra del dios, o un río o
el imperio o la configuración de los astros [...] Quizás
en mi cara estuviera escrita la magia, quizá yo mismo
fuera el fin de mi busca. En ese afán estaba cuando me
recordé que el jaguar era uno de los atributos del dios.

JoRGE LUIS BORGES

(El Aleph 1971: 119)

\section{Introducción}

Desde el periodo preclásico, en la iconografía mesoamericana se ha representado de manera predominante una bestia mítica: el jaguar. Su figura aparece reiteradamente a través de tres mil años. Las innumerables representaciones de este felino han asumido, a lo largo de este tiempo y según la cultura productora del ícono, todas las formas imaginables, tanto realistas como estilizadas o abstractas. Entre esta variedad se hace notar una imagen que destaca por su muy extraño carácter, pero también por su misteriosa belleza: el jaguar reticulado teotihuacano.

Es éste un ente fantástico ampliamente difundido en la pintura mural de la gran ciudad prehispánica, presente en distintos edificios. Su rasgo principal consiste en haber sido despojado de su característica piel moteada, así como de su corporeidad. En vez de ello, está constituido por una retícula de ondulados diseños entrelazados que conforman la cabeza, el tronco, las patas y la cola. De sus fauces entreabiertas con frecuencia emerge una vírgula (figura 1) que expresa un rugido. La fiera 




Figura 1. Jaguar reticulado (detalle). Atetelco, Patio Blanco, Pórtico 2, muro Este, pintura mural. Teotihuacán, Estado de México, cultura del Altiplano central/teotihuacana, Clásico, in situ. Dibujo de Rubén Rosas.

muestra las encías de la mandíbula superior, enseñando los colmillos y los incisivos. Su nariz es chata, su lengua bífida recuerda la de las serpientes, mientras que sus garras retractiles se corresponden con las de los gatos. Cuando la efigie mira de frente adopta, como se verá más adelante, una convención pictórica mesoamericana que data del periodo preclásico y sigue vigente hasta el postclásico: la de un rostro terrible compuesto por dos perfiles que al enfrentarse conforman una sola imagen frontal (figura 2). ${ }^{1}$ Su contexto pictográfico inmediato está constituido por símbolos que aluden al ámbito acuático. Entre ellos, deidades relacionadas con el precioso líquido; plantas a manera de axis mundi, de cuyas flores brotan chorros de agua con ojos divinos (figura 2); cenefas inferiores en forma de bandas o gruesas franjas que representan la superficie del agua (figuras 2 y 3), así como otras franjas que enmarcan a las quiméricas fieras zoomorfas y que están llenas de conchas bivalvas y de caracoles.

Sobre la base de los mitos, de las fuentes primarias y secundarias, así como de la analogía etnológica, se perfila la imagen de un jaguar demiurgo, promotor a la vez que destructor del universo. En este sentido, Mercedes de la Garza afirma que para los pueblos mayas el jaguar "pro-

Vid. Rubén Cabrera y Beatriz de la Fuente (De la Fuente 1995: 75 y 324) y María Elena Ruiz Gallut (2005: 31). 


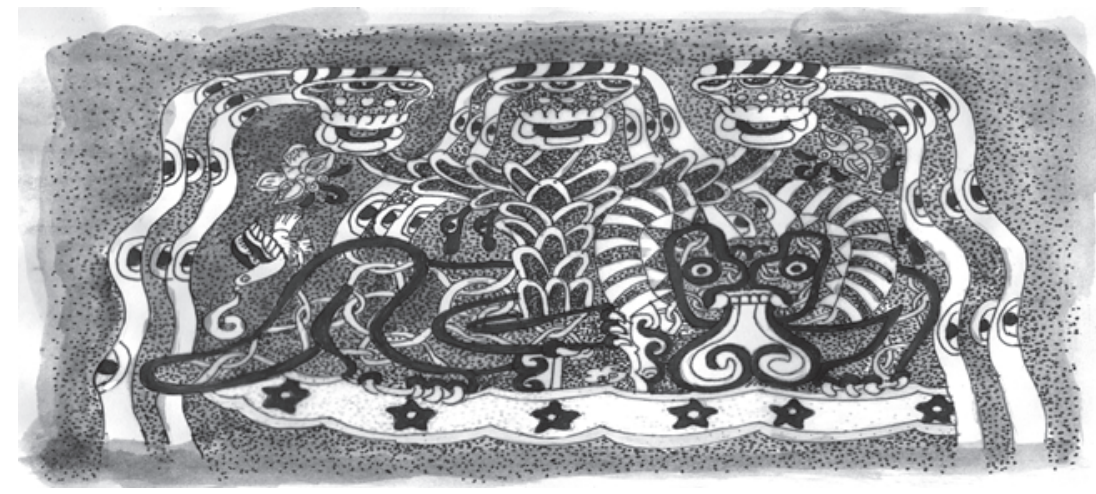

Figura 2. Jaguar reticulado (detalle). Zona 5 A, Conjunto del Sol, Pórtico 13, pintura mural. Tepantitla/Teotihuacán, Estado de México, cultura del Altiplano central/teotihuacana, Clásico, in situ. Dibujo de Rubén Rosas.

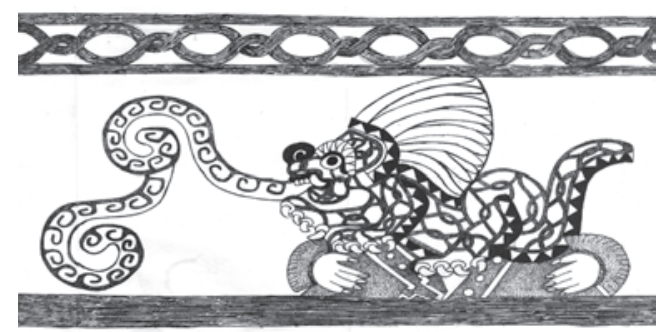

Figura 3. Jaguar de agua o jaguar reticulado (detalle). Pórtico 10, Conjunto de los Jaguares, pintura mural. Teotihuacán, Estado de México, cultura del Altiplano central/ teotihuacana, Clásico, in situ. Dibujo de Rubén Rosas.

viene de un mundo anterior al actual, un tiempo primordial caótico, precósmico" (De la Garza 1998: 131). Entre los nahuas, como también en el área maya, según la investigadora "el jaguar no sólo representa el estado previo al orden actual del universo, sino también la fuerza destructora que le pondrá fin" (De la Garza 1998: 132). Por su parte, Alfredo López Austin afirma que los antiguos mixtecos creían en una dualidad creadora andrógina, a cuyo aspecto masculino le llamaron "Culebra de León", mientras que a su aspecto femenino "Culebra de Tigre"2 (López 1994: 80). Este ser fantástico es, según María del Carmen Valverde, un

2 El jaguar (Pantehera onca) aparece nombrado como tigre a pesar de que no existe el tigre en América. 
símbolo que reina en "la parte oscura del universo", en "el espacio no socializado por los hombres" (Valverde 2005: 48). La antropóloga va todavía más lejos cuando ubica al felino en contraposición no sólo con el mundo ordenado por el hombre, sino en una dimensión más allá del panteón de los dioses, donde los poderes omniscientes de los felinos míticos "superan a las fuerzas del orden e incluso pasan por encima de los poderes de las deidades" (Valverde 2005: 49).

Según diversos mitos mesoamericanos, cuando el mundo estaba por nacer, ahí ya estaba el jaguar. Antes de la aparición del sol, antes de cualquier distinción, el felino mítico ya merodeaba en la oscuridad primigenia. Era él, in illo tempore, el señor de aquel tiempo sagrado e inicial, era él quien personificaba a las potencias caóticas que precedieron a la creación del mundo. Y siguiendo una simetría implacable, también era el jaguar el responsable del trance apocalíptico que iba a llevar al mundo de vuelta a la oscuridad primera. Su aterradora presencia era la señal del fin de las eras, su rugido era la voz del trueno, presagio nefasto. El Sol se tornaba negro conforme él lo iba devorando. Los imperios declinaban tan pronto como él aparecía. Siendo el amo de la noche, reinaba en el caos primordial, asociado a lo salvaje, a lo inculto, a lo indómito, a lo terrible, a lo prohibido, pero, asimismo, a lo sagrado. Lejos de pertenecer a la realidad inferior de las cosas ordinarias, él era, él mismo, la hierofanía por excelencia.

Se entiende entonces que, en esta galaxia de contenidos, el jaguar, o mejor dicho, este híbrido felino-serpentino, fuera la bestia elegida para representar la fuerza cosmogónica contrapuesta al "espacio 'cultural' dominado" (Lotman 1996: 27) - así como estructurado y organizadopor los dioses en cuanto señores del tiempo y del espacio. Así, los pueblos mesoamericanos ubicaron al jaguar, como demiurgo y destructor del universo, entre el espacio ordenado, creado por los dioses y habitado por los hombres, por un lado, y el mundo no semiótico externo, el caos primordial, por el otro. Sin embargo, no ha quedado claro, en los análisis realizados hasta ahora (González 2001; Matos 2016), por qué los pueblos mesoamericanos eligieron justamente al jaguar para desempeñar ese rol.

El presente trabajo postula que allí donde muchos investigadores han visto tanto la representación de un animal o un conjunto de símbolos de apariencia zoomorfa, como un panteón de dioses con rasgos felinos 
o ataviados con atributos del jaguar (figura 4), se encuentra algo de naturaleza completamente distinta al aspecto zoomorfo. Este ensayo propone que el jaguar, en el contexto del lenguaje plástico mesoamericano, no es un animal (el animal en sí no es importante) ni un símbolo, sino una metáfora del estruendo del verbo creador encarnado. ${ }^{3}$ El rugido del jaguar está relacionado, siempre en el plano metafórico, con el trueno, en cuanto verbo creador que acompaña a la hierofanía fulgurante del rayo en la aurora de los tiempos, tal y como se describe este fenómeno meteorológico en multitud de mitos cosmogónicos.



Figura 4. "Quetzalcóatl rojo" o "Dios Jaguar emplumado", efigie con yelmo de jaguar reticulado de modo que parece surgir de entre las fauces del felino mítico. Zacuala,

Pórtico 2, mural 2, pintura mural. Teotihuacán, Estado de México, cultura del Altiplano central/teotihuacana, Clásico, Museo Nacional de Antropología, Ciudad de México. Dibujo de Rubén Rosas.

Para comprobar esta hipótesis, realizaré un análisis hermenéutico del ícono del jaguar reticulado, pretendiendo arrancar el velo que oscurece la misteriosa imagen, no sólo por causa de "la distancia temporal (de por sí ya suficiente para este propósito) sino [...] [por] la ambigüedad en el uso de la metáfora" (Wind, apud Agamben y Ferrando 2014: 39-40). Indagaré los diferentes aspectos formales del ícono teotihuacano, a saber: su cara frontal, constituida por dos perfiles

\footnotetext{
En la expresión "verbo creador encarnado" no debe leerse ninguna analogía con la cosmovisión judeocristiana. La expresión se usa en el sentido más genérico y universal de la noción de la divinidad encarnada en cuya boca se materializa el verbo eterno que contiene, une y despliega hacia la existencia todo en cuanto existe.
} 
enfrentados; el ámbito acuático de la oscuridad primera donde aparece y la característica retícula de sinuosos diseños entrelazados que conforma su cuerpo. Someteré cada uno de estos aspectos a un estudio comparativo con otras obras del arte mesoamericano de características y contenidos similares, a fin de descubrir el significado oculto en ellos. El fundamento ideológico de este proceder consiste en que tras el conjunto de todas las obras plásticas en torno al jaguar se debe revelar un solo discurso cosmogenésico, un solo lenguaje metafórico que hubieron de compartir todas las culturas mesoamericanas. Es decir, que el discurso de los orígenes constituye en el pensamiento mesoamericano una constante que no se limitó a un ícono concreto, tal como lo es, por ejemplo, la imagen del jaguar reticulado, y tampoco a una cultura o una época específica, sino que se desarrolló (plásticamente) a lo largo de tres mil años y puede descifrarse como un discurso. Seguidamente, integraré los elementos analizados para restituir un texto global del momento cosmogenésico, a partir del cual sea posible dilucidar el misterio del jaguar reticulado en concreto. Como dice E. Wind, en el lenguaje plástico, al igual que el lenguaje literario, "la presencia de un significado irresuelto es un obstáculo para el disfrute del arte" (Wind, apud Agamben y Ferrando 2014: 40).

\section{La cara frontal formada por dos perfiles en el arte mesoamericano}

Cuando los estudiosos de los íconos teotihuacanos, como Rubén Cabrera y Beatriz de la Fuente, describen - en cuanto convención pictórica propiamente teotihuacana - la representación del rostro del gran jaguar reticulado como un semblante desdoblado que mira al espectador de frente y que está formado por dos perfiles enfrentados (De la Fuente 1995: 75 y 324), es necesario precisar que no sólo se trata de una particularidad propia de la expresión artística de esta gran urbe. Es posible encontrar este tipo de caras trinitarias en todas las culturas mesoamericanas, desde la cultura olmeca, la llamada cultura madre, que apareció más de mil años antes de Cristo, hasta la cultura mexica en el momento del contacto con los españoles en el siglo XVI. 
Durante los primeros mil años de vida civilizada mesoamericana, es decir urbana, la encarnación monstruosa de la cara trinitaria se encontraba apegada a cánones rígidos, casi inamovibles. Ello condujo a la conformación de una sola figura emblemática: el dragón olmeca. Una fiera mítica extremadamente estereotipada que se caracterizaba por su estrecho margen de variedad e innovación plástica y que, como motivo principal del arte de aquella época, llevó a Covarrubias a nombrar a los pueblos productores de estas obras como "pueblos del jaguar". Los rasgos más característicos y en extremo estilizados, además de antropomorfos, de estos dragones consisten en: cejas flamígeras o aserradas que aluden a halos de fuego, labios carnosos y gruñidores con comisuras colgantes, y una hendedura en forma de " $\mathrm{V}$ " en la parte superior de la cabeza. Vemos esta inconfundible combinación de rasgos en innumerables hachas votivas olmecas (figura 5), las cuales generalmente han sido asociadas al trueno. Covarrubias llega a hablar de "un dios jaguar del trueno" (Covarrubias, apud González 2001: 130), mientras Yolotl González Torres relaciona a esta deidad "con el trueno, con la oscuridad y con el agua" (González 2001: 140). Y aunque no todos los especialistas concuerdan con la idea de que estas figurillas atigradas representan dioses, la asociación entre el jaguar, el trueno y demás fenómenos relacionados con la tormenta eléctrica se reitera indefectiblemente. Marcus Joyce, por ejemplo, "propone que representan fuerzas de la naturaleza, relámpago y terremoto" (Joyce, apud Clark 2008: 165). Amén de innumerables mitos y rituales indígenas que refuerzan la idea de tal vínculo. En un mito lacandón el sonido del trueno equivale al temido "rugir del jaguar celeste" y una fuente del México central describe un ritual totlimpaneca donde "el sacrificio de un jaguar rojo [...] desencadenó el trueno" (Olivier 2004: 193 y 179).

Regresando a la plástica olmeca, así como a la cuestión formal del semblante desdoblado, se puede observar que todas estas hachas muestran un rostro que mira de frente, sin que se puedan distinguir, a primera vista, los dos perfiles encontrados que lo constituyen. Fue Rubén Bonifaz Nuño el primero en advertir que tras estos semblantes que se esmeraron en plasmar los olmecas con un ahínco parecido a una obsesión (Soustelle, apud Bonifaz 1989: 77), se disimulaban dos perfiles 


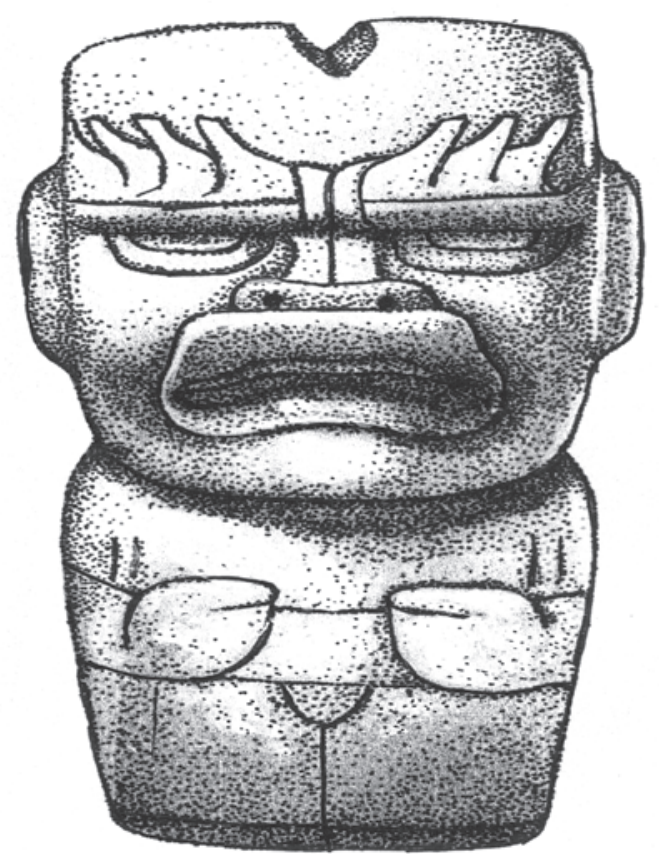

Figura 5. Hacha olmeca, de la antigua colección de William Bullock (adquirida por el Museo Británico en 1825), escultura en jade. Procedencia desconocida, cultura olmeca, Preclásico. The Trustees of the British Museum, Londres, Inglaterra. Dibujo de Rubén Rosas.

de serpientes. Y aunque este autor, al advertirlo, termina negando que la presencia de la cara frontal se relacione con el jaguar, tiene toda la razón al señalar que el monstruoso semblante contiene dos serpientes de perfil, y llegar a la conclusión de que no se trataba "de una representación del jaguar, como Covarrubias propone y muchos aceptan [...] [sino que] había que concluir que la llamada 'boca de jaguar' olmeca no es tal; ni siquiera que es una boca de serpiente [...] sino la estilización de perfil de dos bocas de serpientes que se tocan" (Bonifaz 1989: 77).

No resulta fácil percibir este semblante figurado si no se está familiarizado con el juego visual implicado en el rostro trinitario, o si se carece de la sensibilidad artística necesaria para distinguirlo. Si uno se toma la libertad de desdoblar al dragón con la ceja flamígera y la cola de zarpa de jaguar estilizado que aparece esgrafiado en un botellón de Tlatilco 
(figuras 6a y 6b), y se compara el resultado con las caras que miran de frente en las hachas olmecas, resulta más fácil ver que la cara del jaguar está constituida por dos perfiles viperinos que se encuentran, en este caso, a la altura de los ojos. De modo que es legítimo hablar de dos caras de serpientes de perfil que al unirse conforman un solo rostro felino viendo frontalmente, o sea, que la quimera es un híbrido tanto felino como viperino que conforma un solo ente conceptual, constituyendo de esta manera una convención plástica que se encuentra presente en el arte mesoamericano desde sus inicios en la cultura olmeca.



Figura 6a. Dragón olmeca con ceja flamígera que lleva como cola una garra de jaguar estilizada, botellón cerámico con diseño esgrafiado. Tlatilco, Estado de México, cultura del Altiplano central/olmeca, Preclásico. Museo Nacional de Antropología, Ciudad de México. Dibujo de Rubén Rosas.

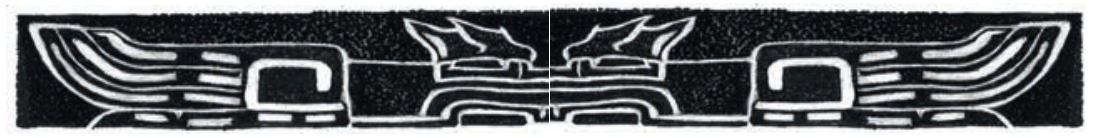

Figura 6b. Dragón olmeca de perfil con cejas flamígeras y cola en forma de una garra de jaguar estilizada, botellón cerámico con diseño esgrafiado. Tlatilco, Estado de México, cultura del Altiplano central/olmeca, Preclásico. Museo Nacional de Antropología, Ciudad de México. Dibujo de Rubén Rosas.

Si posteriormente ya no hubo de existir una figura tan emblemática como lo había sido el dragón olmeca, y si éste pareció haberse extinguido sin dejar sucesores tan estereotipados, ello se debió, si admitimos una explicación en términos plástico-formales, al hecho de que la gran ciudad subsiguiente, Teotihuacán, relajó la canonización de la representación monstruosa. Durante los más de seiscientos años de la existencia de esta megaurbe, el ser mítico de la cara híbrida fue objeto de una verdadera revolución plástica. Se reconfiguró la fisionomía del dragón, innovando sus perfiles y su frente, mas no su concepción hierofánica, herencia de las caras trinitarias de la cultura olmeca. En la pirámide de Quetzalcóatl (figura 7) aparecen dragones de perfil cuyos cuerpos 
sinuosos han sido cubiertos de plumas preciosas y que serpentean a lo largo de los taludes, pero cuyas caras también aparecen esculpidas de frente sobre los tableros o las alfardas de la misma pirámide y presentan, a pesar de conservar la lengua bífida, características principalmente felinas: el hocico breve, la nariz chata, la cabeza redonda, el labio leporino y la dentición de los jaguares.



Figura 7. Fachada poniente de la Pirámide de Quetzalcóatl/Ciudadela, compuesta por esculturas y relieves en basalto. Teotihuacán, Estado de México, cultura del Altiplano central/teotihuacana, Clásico, in situ. Dibujo de Rubén Rosas con base en un dibujo de José Villaseñor, Proyecto de pintura mural prehispánica en México, IIE-UNAM (PLPMPM).

De modo que, mientras el artista olmeca se encontraba sometido a cánones formales que conformaban conjuntos de reglas y preceptos que estaba obligado a seguir si pretendía producir una pieza reconocida y aceptada por la sociedad, el artista teotihuacano, en cambio, amparado por cánones mucho más flexibles, produjo una explosión creativa, generando una fascinante calidoscopia de la representación de la fiera que heredaron las culturas subsiguientes (Müller 2016: 248-253). Se trata, a pesar de las diferencias formales, no de un ser distinto al anterior, sino tan sólo de distintas soluciones formales que los artistas descubrieron al enfrentar el reto plástico de representar una sola cara felina frontal constituida por dos caras de serpiente de perfil. Por lo tanto, la forma en que se encuentra plasmado este misterio cosmogenésico encarnado es, en términos iconológicos, secundaria y hasta irrelevante.

Se puede hablar de esta fiera felina-serpentina cada vez que vemos un semblante que mira de frente y que está representado mediante dos perfiles. No importa que los perfiles serpentinos se junten a la altura de los ojos, como es el caso en la máscara de piedra olmeca de La Venta (figura 8), la cual es discernible como una cara conformada por dos per- 
files tan sólo gracias a la presencia de las cejas flamígeras; o que, como en la efigie del llamado Tlaloc de Uhde (figura 9), las características cejas flamígeras hayan sido sustituidas por serpientes enrolladas que ahora enmarcan los ojos (formando las llamadas anteojeras estilizadas), y el encuentro de las dos cabezas viperinas se realice a la altura de la boca.



Figura 8. Máscara con boca gruñidora de jaguar y cejas flamígeras, escultura en piedra. La Venta, Tabasco, cultura del Golfo/olmeca, Preclásico. Museo Nacional de Antropología/Sala Golfo de México, Ciudad de México. Dibujo de Rubén Rosas.

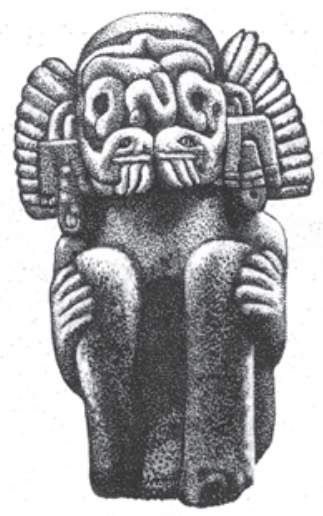

Figura 9. "Tlalóc de Uhde" cuyo semblante está conformado por dos serpientes que se juntan a la altura de la boca mientras sus sinuosos cuerpos conforman lo que se conoce como anteojeras. Procedencia desconocida, probablemente cultura del Altiplano central, Postclásico. Colección Museo Etnográfico de Berlín, Alemania.

Dibujo de Rubén Rosas. 
La cara trinitaria del monstruo también se puede apreciar en una pieza maya constituida por los dos huesos de la mandíbula inferior de un felino (figura 10), en los cuales ha sido esgrafiada una serpiente cuyas cejas flamígeras parecen estar constituidas por la dentición del maxilar. Al juntarse las dos piezas óseas, las sierpes se enfrentan de perfil y forman el semblante de un solo jaguar.


Figura 10. Dos mandíbulas de felino con serpientes míticas grabadas sobre el maxilar inferior de un felino. Procedencia desconocida, cultura maya. Gran Museo del Mundo Maya de Mérida/Sala 4: Mayas ancestrales, Mérida, Yucatán.

Dibujo de Rubén Rosas.

El mismo fenómeno se repite en el caso de numerosos santuarios, donde la misma entrada al recinto está constituida por las fauces del dragón; por ejemplo, en el templo monolítico de Malinalco (figura 11). También aquí, como en el caso de las hachas olmecas que revelaron su naturaleza de semblante trinitario al ser comparadas con el diseño esgrafiado en el botellón de Tlatilco, el hecho de ver en el acceso al recinto una representación más del monstruo del rostro trinitario se justifica al ser comparado con el perfil de la monumental escultura mexica de la Xiuhcóatl (figura 12). Como su nombre lo indica, se trata de una serpiente de fuego, de una serpiente preciosa. O sea, que la entrada monstruosa a este recinto puede entenderse como la representación de dos serpientes de fuego enfrentadas que conforman un solo semblante frontal de jaguar. En estas piezas presenciamos una representación surreal que amalgama aspectos singulares de las dos bestias para crear una sola imagen hierofánica. No cabe hablar de un jaguar, como tampoco de una serpiente, o mejor dicho de dos serpientes, sino de una sola creación conceptual: el gran dragón. 


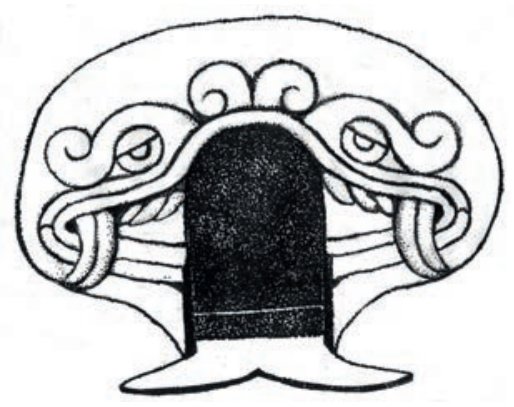

Figura 11. Entrada al santuario de Malinalco, Estructura I. Malinalco, Estado de México, cultura del Altiplano central/mexica-azteca, Postclásico, in situ. Dibujo de Rubén Rosas.

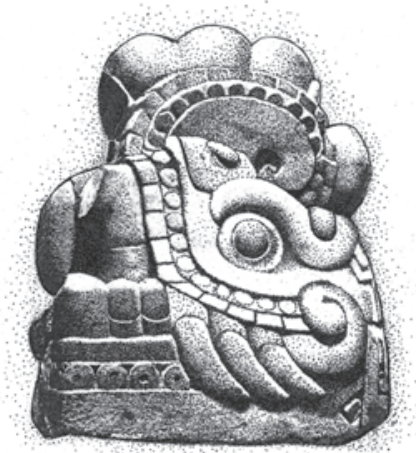

Figura 12. Xiuhcóatl o "Serpiente Histórica de la Ciudad de México, cultura del Altiplano de turquesa", escultura en basalto. Jardín de la Catedral Metropolitana/ Centro central/mexica-azteca, Preclásico. Museo Nacional de Antropología, Sala Mexica, Ciudad México. Dibujo de Rubén Rosas.

Una vez familiarizados con el semblante trinitario del dragón serpiente-jaguar, lo podemos encontrar por doquier. Descubrimos entonces que "no existe ninguna composición iconográfica donde el dragón no figure de una u otra forma, ya sea como protagonista, como marco o fondo de escena representada, como trono, como insignia o como ornamento arabesco mesoamericano" (Müller 2016: 17). Siempre que exista un jaguar se encuentran, sin duda alguna, dos serpientes.

Al observar un cuauhxicalli mexica - recipiente destinado a recibir los corazones de los sacrificados-, cuyo altorrelieve tallado en piedra muestra dos serpientes gemelas emplumadas (figura 13), es posible ver, 
al igual que en todos los casos anteriores, dos perfiles viperinos enfrentados. Es una imagen que parece estar reflejada en un espejo, o sea, una "imagen que se hace pasar por el reflejo de un ser, o el ser de un reflejo" (Bachelard, apud Lecourt 1982: 47). La diferencia, aquí, es que el encuentro entre ambos crótalos, aunque parece inmanente, aún no se ha llevado a cabo. La cara felina monstruosa que mira de frente todavía no se ha constituido. Sin embargo, esta fusión de los dos ofidios ígneos en favor de un solo semblante monstruoso frontal tiene lugar en otra pieza, quizá la más conocida del arte mexica, la monumental Coatlicue (figura 14), también conocida como la madre de los dioses. Aquí el encuentro de los dos reptiles ya se ha consumado. Dos vigorosas víboras emergen cuan chorros de sangre del cuello cercenado de la deidad. Sus cuerpos se tuercen sobre sí mismos, de modo que las cabezas, vistas de perfil, se juntan para conformar el eje del rostro hierático de la divinidad. Aparece así el tercer semblante, un rostro con rasgos felinos esquematizados que emerge entre las dos culebras. Un rostro terrible y omnipresente, sin frente ni revés, dado que, aun al ver la pieza por detrás, podemos apreciar el mismo semblante monstruoso, conformado por una idéntica representación de dos perfiles de serpientes encontradas. En la Coatlicue, obra maestra de la lapidaria mexica (y universal), la transposición de las formas permitió, al igual que en todas las piezas mencionadas, la creación de una fisonomía donde la fusión de dos perfiles encontrados genera - elemento surreal por excelencia - un solo rostro que mira de frente. Un ser fantástico que, a pesar de no participar de la materialidad de este mundo fenoménico, encarna el principio del ser y del existir. Con todas estas obras estamos ante una interminable reiteración formal y conceptual que se llevó a cabo a lo largo de tres milenos en la cultura mesoamericana, y que siempre, de nueva cuenta, consistía en un sólo rostro hierofánico constituido por una xiuhcóatl, serpiente de fuego, y su reflejo, cuyo encuentro implica, de manera latente, la posibilidad de componer un rostro monstruoso frontal, en cuyas fauces parece que está a punto de emerger un gran estruendo, un monstruoso sonido ensordecedor.

En estas expresiones artísticas de las culturas mesoamericanas están presentes, uno tras otro, todos los atributos ineluctables del arte mágico que el antropólogo Leonard Adam ha catalogado no tanto con base en el aspecto externo de las obras analizadas, sino en su coherencia 




Figura 13. Cuauhxicalli, recipiente para los corazones de los sacrificados, escultura en andesita. Calle 5 de Mayo y Bolívar, Centro Histórico de la Ciudad de México, cultura del Altiplano central/mexica-azteca, Postclásico, Museo Nacional de Antropología, Sala Mexica, Ciudad de México. Dibujo de Rubén Rosas.

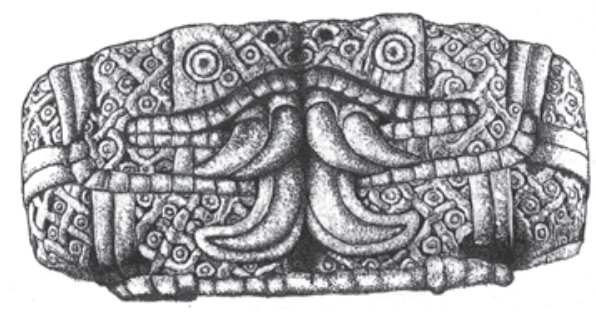

Figura 14. Coatlicue (detalle), detalle de la cabeza del monolito de basalto. Templo Mayor/Ciudad de México, cultura del Altiplano Central/mexica-azteca, Postclásico,

Museo Nacional de Antropología/Sala mexica, México. Dibujo de Rubén Rosas.

conceptual interna, cuya vigencia universal ha sido postulada por Levy-Strauss, ${ }^{4}$ a saber: el simbolismo - al que me atrevo a añadir el metaforismo-, el surrealismo, la estilización, la esquematización, la simetría, el antirealismo conceptual y, por último, la imagen de lo sacro mediante la representación de "un individuo visto de frente, mediante 'dos' perfiles" (Levy-Strauss 1968: 222), imagen en verdad sorprendente porque no se trata de una coincidencia. Leonardo da Vinci se atrevió a postular que "la deidad que tiene la ciencia del pintor hace que su mente se transmute en semejante a la mente divina" (Da Vinci,

$4 \quad$ El mérito de Leonard Adam consistió en haber catalogado, utilizando un criterio formal-comparativo, las semejanzas icónicas de las representaciones de lo sagrado de dos áreas culturales distintas y distantes entre sí: el arte primitivo de la costa de América y el de la China arcaica. Posteriormente, el etnólogo Lévy-Strauss postuló la vigencia universal de estos atributos después de analizar, en este sentido, la expresión plástica de los maorís de Nueva Zelandia, el arte neolítico de Amur, las expresiones plásticas de la costa noroeste norteamericana y de las culturas neolíticas, así como las de China y Japón (Lévi-Strauss 1968: 222-224). 
apud Juanes 2009: 59). De modo que fueron los artistas prehispánicos, sirviéndose de los atributos descritos por Adam, los responsables de crear las mil caras del dragón mesoamericano. Gracias a sus manos y su genio, a lo largo de muchas generaciones el dragón se convirtió en una realidad objetiva siempre cambiante, siempre inconclusa. Le tocaba al creador de estos íconos ya sea conservar, ya sea renovar el ser fantástico-mítico, gracias a un juego combinatorio casi infinito vuelto posible por los atributos constituyentes del arte mágico. Un arte cuyo objeto fundamental no ha sido nunca mimético, ni siquiera estético, y cuya finalidad, por lo tanto, no ha consistido en recrear la naturaleza ni en crear objetos bellos, sino en hacer posible la encarnación de lo sagrado.

De lo expuesto hasta aquí se deduce que para los pueblos mesoamericanos el jaguar no fue el único animal ubicado en este espacio extrasemiótico no organizado que se relaciona tanto con el caos primordial como con la fuerza creadora y precosmogónica, sino que hay otra bestia inextricablemente unida a la imagen del felino: la serpiente o, mejor dicho, y en ello consiste el quid de la cuestión, el ofidio desdoblado como reflejo especular, a manera de un semblante trinitario. Por consiguiente, todo lo que se ha dicho respecto al jaguar puede ser aplicado igualmente a esta otra fiera desdoblada. Ambos, inextricablemente unidos, comparten su condición indistinta caótica, a la vez que creadora, no buscando representar la realidad sino, por el contrario, construir la realidad.

Así, la pregunta expuesta al principio de este ensayo sigue en pie, aunque requiere ser precisada: ¿Por qué los pueblos mesoamericanos eligieron para desempeñar el papel de demiurgo justamente al ícono del jaguar que surge del enfrentamiento de dos serpientes?

\section{El jaguar mítico, el espejo de las aguas prístinas y la metáfora}

Para saber por qué en el arte mesoamericano se escogió la figura de un híbrido monstruoso, entre felino y serpiente, para representar al misterio tremendum, en cuanto fuerza bruta encarnada que dio origen al universo, es menester ver la relación que guarda ese ente quimérico con el mundo caótico precósmico del cual, según los mitos, es el amo y 
señor. En un principio, de acuerdo con el Popol Vuh, el libro del consejo de los maya quiché,

[...] sólo el cielo existía. La faz de la tierra no aparecía; sólo existían la mar limitada, todo el espacio del cielo. No había nada reunido, junto. Todo era invisible, todo estaba inmóvil en el cielo. No existía nada edificado. Solamente el agua limitada, solamente la mar tranquila, sola, limitada. Nada existía. Solamente la inmovilidad, el silencio, en las tinieblas, en la noche (Popol Vuh 1993: 4).

En términos plásticos, no habría nada que representar. El ojo, si uno se figura un ojo que observara este escenario, podría ver, valga la paradoja, que no se veía nada: un espejo de agua quieta y silenciosa que nada reflejaba, a falta de luz, en medio de una noche eterna. Pero allí estaban esparcidos, según esta misma tradición oral, recogida en grafía latina, el "Maestro Gigante (Relámpago), Huella del Relámpago, Esplendor del Relámpago, Espíritus del Cielo, Espíritus de la Tierra, Constructores, Formadores, Procreadores, Engendradores" (Popol Vuh 1993: 8). De modo que, en aquel tiempo mítico, el cual aún no había visto la primera aurora, sí existía esporádicamente luz. En este mismo sentido, los huicholes advierten que detrás del padre Sol está el abuelo rayo y los totonacos hablan del trueno que es anterior a la aparición del Sol (González 2001: 187). Los mixes representan esta luz primera en la forma de rayos montados en tigres que luchan entre sí, mientras que los mixtecos se la figuran como culebras-leones y culebras-tigres. Aunque son mitos distantes en el tiempo y el espacio, se perfila un único relato de origen compartido por todos los pueblos mesoamericanos relacionado con una gran tormenta cósmica anterior al primer amanecer. Y también dos metáforas zoomorfas asociadas al instante inaugural del cosmos: los jaguares y las serpientes.

El hombre arcaico (cuya fuerza de destrucción no había superado todavía a la de la naturaleza) no podía imaginar un espectáculo de mayor ímpetu ni de mayor violencia, ni de mayor fuerza iracunda de destrucción, ni de mayor fuerza de renovación como la contenida en el fenómeno atmosférico de la tormenta, momento en que tanto el fuego como el agua caen del cielo. El rayo, al estallar sobre el espejo de las aguas del océano primigenio se duplica mediante su reflejo, asemejándose a dos 
serpientes de fuego que se enfrentan mutuamente y entre cuyas fauces explota el trueno. El rayo es a la vez dos entidades complementarias, el reflejo y el reflejante, para usar la terminología que utilizó Sartre para exponer su "díada fantasma reflejo-reflejante" (Sartre 1986: 203). El numen luminoso en cuanto reflejante (la cosa que genera el reflejo) y su reflejo zigzagueante en el oscuro espejo de las aguas, era luz en plena oscuridad, unión del fuego y del agua, comunión de lo penetrante y lo penetrado, del calor celeste y el frío terrestre, del arriba y el abajo. Era la metáfora en que coincidían todos los contrarios; la metáfora, por ende, de lo absolutamente perfecto, de lo hierofánico per se.

De este modo se ha verificado la hipótesis del presente ensayo: el dragón en la iconografía mesoamericana no representa un animal ni un felino, ni una sierpe, sino algo de naturaleza completamente distinta. La serpiente de fuego se corresponde con una serpiente de luz, la cual es la metáfora visual del rayo cosmogónico que se desploma en la mar de los orígenes, mientras que el jaguar es el equivalente de una metáfora auditiva asociada a la metáfora visual. El rugido del felino, representado en la iconografía como un solo semblante de jaguar que ve de frente, se relaciona, siempre en el plano metafórico, con el trueno en cuanto verbo creador, inextricablemente unido a la hierofanía fulgurante. El felino es la imagen del trueno que detona en medio de dos serpientes de fuego. Los tres elementos conjuntamente conforman el rostro trinitario del ícono del gran dragón, fundamento principal e ineluctable del arte sacro mesoamericano. Por consiguiente,

[...] ni la serpiente ni el jaguar se inscriben dentro de una taxonomía zoológica donde la víbora en cuanto reptil y el jaguar en cuanto felino no comparten nexo alguno, sino que el ícono monstruoso explora a partir de la metáfora visual del rayo, oculta en las sierpes ígneas, [...] aunada a la metáfora auditiva que hace coincidir el estruendo del trueno con el rugido ensordecedor del jaguar, nuevos principios plásticos, sistemas y fines de clasificación que rastrean, en un plano icónico, las relaciones internas de semejanza entre el concepto de lo absoluto y sus metáforas: el rayo, la serpiente de fuego y el trueno figurado en forma de jaguar, ofreciendo con ello al espíritu un juego ilimitado de imágenes" (Müller 2016: 35). 
La riqueza imaginativa derivada de las metáforas de la fuerza divina se ve reflejada en la riqueza iconográfica correspondiente, en la cual predomina la metáfora zoomorfa de la cara trinitaria de la serpiente de fuego-jaguar. No se trata del único modo posible de representar plásticamente el momento de la detonación luminosa que impulsó la creación del mundo, pero, eso sí, de su expresión más original y espectacular. Los artistas mesoamericanos, en una verdadera explosión creativa, se sirvieron tanto de las enormes fauces que caracterizan a ambos animales y de los prominentes colmillos de la sierpe y el felino, como también aprovecharon la semejanza entre la piel atigrada de los crótalos y las características manchas del pelaje del jaguar mesoamericano, a fin de crear no sólo semblantes felinos formados por dos perfiles viperinos, sino de combinar elementos de ambos animales para encarnar un monstruo fantástico que era la representación plástica de la creación del cosmos. Por lo tanto, es posible encontrar, entre otros innumerables ejemplos, jaguares de lengua bífida (figura 1), sierpes míticas provistas de las garras, de los bigotes y de la dentición del felino, culebras con la piel moteada del jaguar (figura 15), serpientes bicéfalas con dientes de jaguar incrustados (figura 16), etcétera, etcétera.

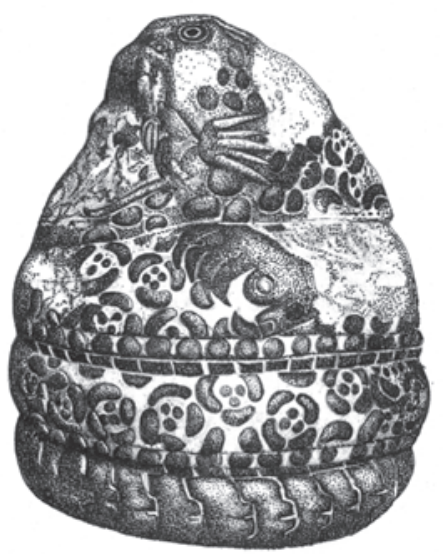

Figura 15. Serpiente-jaguar enrollada, escultura en piedra. Procedencia desconocida, cultura del Altiplano central/mexica-azteca, Postclásico. Staatliches Museum für Völkerkunde, Berlín, Alemania. Dibujo de Rubén Rosas. 




Figura 16. Serpiente de doble cabeza, mosaico de turquesa, coral, concha y dientes de felino sobre madera. Procedencia desconocida, cultura azteca-mexicamixteca, Postclásico. The Trustees of the British Museum, Londres, Inglaterra. Dibujo de Rubén Rosas.

El dragón también se viste de rayos y relámpagos o, mejor dicho, de las abstracciones meteorológicas del fenómeno - líneas en zigzag-, mostrándose, ora predominantemente meteorológico, ora fáunico, ora como una combinación de ambos aspectos y conformando, en conjunto, un híbrido ya no sólo de animales, sino de metáforas zoomorfas y meteorológicas del principio absoluto, sin preocuparse por la legibilidad del resultado. En esta línea, hay dos esculturas teotihuacanas talladas en piedra que representan a un jaguar mítico (figuras 17 y 18), cuyas patas delanteras, en ambos casos, portan las líneas zigzagueantes del rayo, o sea, el rayo y su relejo. Se trata de un sincretismo de expresiones hierofánicas que ha amalgamado distintas maneras de representar el génesis, utilizando una abstracción geométrica, además de atemporal, sustraída de la metáfora del rayo y su reflejo en el espejo del agua, a saber, líneas en zigzag duplicadas, así como otra metáfora auditiva derivada de la del jaguar, la cual alude a la equivalencia del rugido del felino con el rugido del cielo. De nueva cuenta también aquí aparece, en medio del fulgor de las dos serpientes de fuego, el semblante del jaguar mítico, portador del verbo creador, la voz del dios supremo encarnado. ${ }^{5}$ El jaguar y las serpientes de fuego duplicadas gracias al espejo del océano primigenio se convierten en huestes del demiurgo.

5 También aquí, como anteriormente fue el caso de la expresión "el verbo creador encarnado", la locución el "dios supremo encarnado" no debe entenderse en analogía con la cosmovisión judeocristiana, sino en el sentido genérico y universal de la divinidad encarnada. 


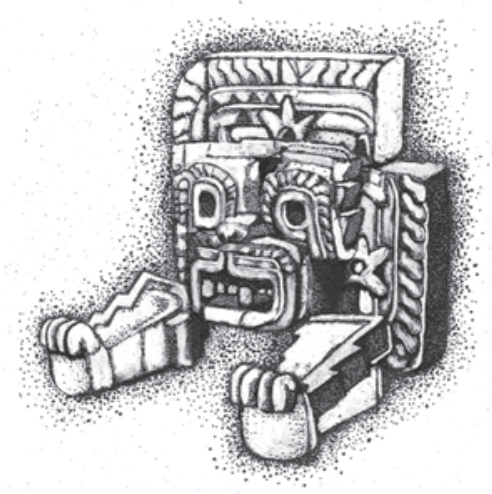

Figura 17. Felino mitológico, escultura en piedra volcánica con restos de estuco y pintura. Teotihuacán, Estado de México, cultura del Altiplano central/teotihuacana, Clásico, Museo Nacional de Antropología/Sala Teotihuacán, Ciudad de México. Dibujo de Rubén Rosas.

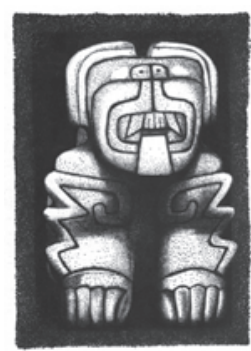

Figura 18. Jaguar mítico, Teotihuacán, Estado de México, cultura del Altiplano central/teotihuacana, Clásico. Museo Nacional de Antropología/Sala Teotihuacán, Ciudad de México. Dibujo de Rubén Rosas.

El jaguar reticulado y la representación de la superficie del agua

El arte sacro tiene una doble misión: no debe ocultarse tras imágenes oscuras e incomprensibles, como tampoco "debe ilustrarse tan claramente que a todos resulte comprensible" (Gerber, apud Izzi 2000: 27). Massimo Izzi suscribe esta opinión cuando señala que existe la "doble necesidad de explicar a los pocos capaces de comprender por una parte y de mantener oculto a los demás por otra", añadiendo que en este discurso, 
"las imágenes animales, como en cualquier otro proceso simbólico, se llevan la parte de león, y entre ellas las figuras híbridas, los monstruos, los acoplamientos de seres infrecuentes, [que] más que cualquier otra imagen, corresponden a las exigencias arriba expresadas" (Izzi 2000: 27). Esto ilustra de manera idónea el enigma del ícono del jaguar reticulado teotihuacano, que ha logrado conservar el carácter misterioso de la red de enlaces ondulados que dan forma a su cuerpo. La respuesta a la pregunta qué es lo que el artista teotihuacano plasmó cuando dibujó esas redes onduladas, debe ser a la vez evidente y ambigua.

Como muchas veces sucede con los misterios, la respuesta se puede encontrar donde menos se espera. En este caso, en un cuadro del pintor inglés del siglo xx David Hockney, a quien le obsesionaba la forma de representar la superficie del agua, no la del mar de los orígenes, sino la de la alberca en su lujosa mansión en Hollywood. Sin embargo, en términos plásticos, el agua es el agua: un pintor que observa su superficie se enfrenta al mismo reto, tanto en una ciudad estadounidense moderna, como en la antigua Teotihuacán. La superficie del agua en sí no puede ser representada. El agua no es más que un espejo y sólo se descubre como tal gracias a las luces u objetos reflejados. Anteriormente vimos que los artistas mesoamericanos estaban plenamente conscientes de esta calidad de espejo que caracteriza al vital líquido, de tal suerte que fue el espejo de las aguas prístinas el que les sirvió de eje imaginario para desdoblar la cara trinitaria del dragón. No sería raro suponer que el mismo ingenio empleado para encontrar muchas maneras formales distintas para representar a la fiera cosmogenésica hubiera sido aprovechado también para recrear plásticamente el contexto al que ésta se vincula inextricablemente, es decir, el escenario oscuro del agua en el océano de los orígenes.

Regresando a Hockney y su cuadro, si se acepta que la ciencia que tiene el pintor es la misma en todas partes y desde siempre, es factible que en dos culturas distintas y en dos épocas distantes se hubiera llegado a la misma solución plástica al buscar un recurso para representar la superficie del agua. En el cuadro Sunbather (figura 19), Hockney representa el agua de su alberca en Hollywood mediante líneas ondulantes que se entrecruzan, formando redes entrelazadas que son formal y conceptualmente idénticas a las redes que aparecen en los jaguares re- 
ticulados. Si aceptamos que, en dos épocas, lugares y culturas distintas sin nexos comunes, los artistas hayan podido llegar a la misma solución plástica, entonces el jaguar reticulado teotihuacano (figuras 1, 2, 3 y 4) podría ser un jaguar cuyo cuerpo representa la superficie del agua o, para ser más exactos, el juego de la luz que dibuja redes luminosas en el espejo del agua. El cuerpo del felino, en este caso, debe entenderse como un tejido de luz que resalta contra el fondo oscuro del mural, siendo la fiera en su totalidad no un animal de carne y hueso, sino un cuerpo de agua, un espejo en medio de las tinieblas primigenias repentinamente iluminadas. Si el rayo, en el arte mesoamericano, se pudo transformar en sierpe, por qué no aceptar que el jaguar se pudo transformar en agua. En tal caso, no cabe imaginar representación más sublime que la de la aurora del cosmos encarnada en el jaguar reticulado, ni mayor destreza y maestría plástica que la de los pintores teotihuacanos.

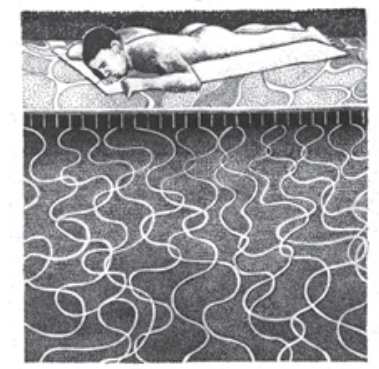

Figura 19. Superficie espejeante del agua. David Hockney, Sunbather/Baño de sol (1966). Museum Ludwig, Colonia, Alemania. Dibujo de Rubén Rosas con base en el cuadro de David Hockney.

Una vez que se acepta la propuesta de que la retícula del felino es una red luminosa que representa la superficie del agua, es posible descubrir representaciones estrechamente relacionadas con esa red, tanto en la forma como en el contenido. En otro mural teotihuacano aparece entre dos sacerdotes un pequeño altar, conocido como el "Escudo de Tlaloc" o como un disco solar (figura 20) (De la Fuente 1995: 158) que probablemente sirvió de marcador portátil en un juego de pelota. Se trata de un disco montado en un pequeño basamento, en cuya parte central se encuentra una red de líneas entrelazadas. En la base hay una franja horizontal con tres escenas que muestran una pelota-sol que rompe dicha 
red, lo cual equivaldría a la superficie del agua primigenia rota por una pelota que representa al astro luminoso. Así, estas pequeñas escenas se revelan como representaciones de la primera aurora, el día uno.

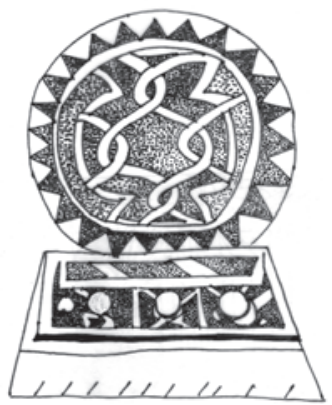

Figura 20. Anillo del juego de pelota. Detalle de una pintura mural, Teopancaxco, Cuarto 1, Mural 1, Teotihuacán-Teopancalco. Teotihuacán, Estado de México, cultura del Altiplano central/teotihuacana, Clásico, in situ. Dibujo de Rubén Rosas.

De modo que se podría postular que el lugar acuoso precósmico y caótico, anterior al mundo, se materializó en la arquitectura mesoamericana en forma de una cancha del juego de pelota. Si el umbral a diversos santuarios era la objetivación de la tormenta cósmica en forma de un monstruo de cara serpentina-felina, metáfora zoomorfa del momento inaugural del cosmos, la cancha del juego de pelota, en cambio, era un escenario arquitectónico monumental que representaba el espejo de agua prístina impregnado con la virtualidad del ser, y que, como tal, sirvió para representar ritualmente el enfrentamiento entre las fuerzas monstruosas opuestas que originaron al mundo.

Otro importante indicio plástico relacionado tanto con el jaguar reticulado como con la idea de que la cancha de pelota, en cuanto espejo de agua, fue descubierto en un sitio maya de Guatemala. Es una pieza de cerámica que muestra una cancha de juego de pelota con la forma de las fauces estilizadas de un jaguar con un dibujo de redes entrelazadas (figura 21). La pieza tiene un contenedor que se comunica con la cancha, de tal suerte que permite inundarla de agua. Esto nos permite pensar que el lugar donde se celebraba el juego ritual era un espejo de agua contenido en las fauces del jaguar mítico. O sea, la pieza sería la visualización de un espacio lleno de agua anterior a la materialización del mundo, lo 
cual es realmente probable si se toma en cuenta que la mayoría de las canchas se encuentran en un nivel más bajo que el de la superficie del suelo y que, en cuanto patios hundidos, sería factible imaginárselos, ya sea real o simbólicamente, como espejos de agua.

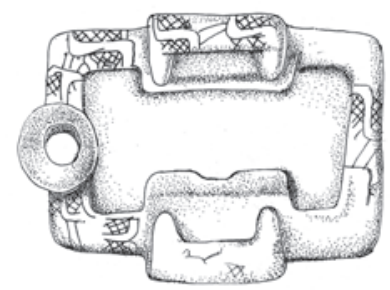

Figura 21. Cancha de juego de pelota en la forma de fauces de jaguar reticulado. Kaminaljuyú, Guatemala, cultura maya, Clásico. Dibujo de Rubén Rosas con base en Eric Taladoire, "Las representaciones bi y tridimensionales de juego de pelota en

Mesoamérica”, Revista Arqueología mexicana. vol. XIX-núm. 117, septiembre-octubre 2012: 18-27, p. 27).

En un relieve de Chichén Itzá hay un detalle que refuerza esta idea. En una de las paredes laterales de la estructura conocida como el "Tzompantli" (literalmente, muro de cráneos), aparece el capitán de uno de los equipos de jugadores del juego de pelota como un guerrero que sostiene en su mano izquierda la cabeza decapitada del capitán del equipo contrario (figura 22). Este personaje se encuentra ante un fondo profusamente decorado con una serie de serpientes y de diseños serpentiformes. De nuevo hay que ver estas sierpes no como animales, sino como metáforas de la superficie del agua. El personaje no se encuentra de pie en medio de un enjambre de serpientes, sino en el espejo de las aguas prístinas. Es posible que esta idea no logre convencer de inmediato al espectador occidental moderno que no conoce el discurso plástico de ataño. De nueva cuenta, un cuadro de David Hockney, de la serie paper pools (figura 23), proporciona la clave para descubrir que las serpientes y las líneas ondulantes y serpentinas integran una representación de la superficie reflejante del agua. Nadie pensaría, al ver esta pintura, en una piscina llena de pequeñas víboras en movimiento, sino simplemente en una alberca llena de agua. Inmediatamente queda claro que las serpientes no son más que un recurso plástico que utiliza zoomórficos centelleos de luz para representar la vitalidad del agua. El 
artista inglés empleó el mismo recurso plástico que habían utilizado los mayas para representar las luces que se reflejan en el agua. Hockney es, sin duda, un gran pintor del agua y también lo fueron los artistas prehispánicos que tallaron en el Tzompantli el mencionado relieve, en el cual los espectadores de entonces vieron a un personaje de pie en un espejo de agua. El artista inglés percibió lo mismo que los artistas prehispánicos observaron y que nosotros mismos podríamos captar al mirar con atención la superficie del agua contenida en una piscina o un lago.

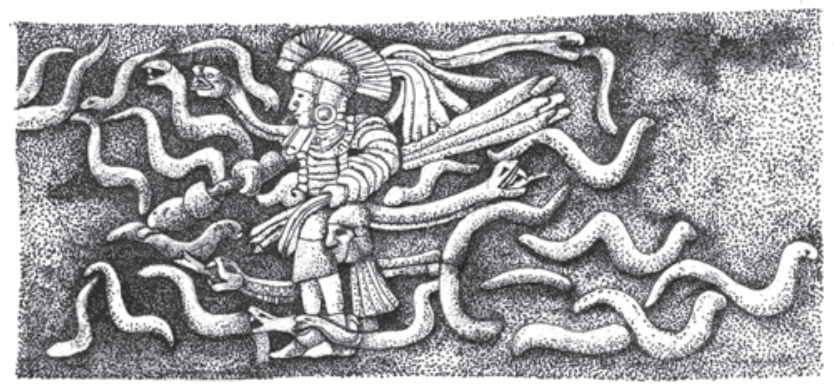

Figura 22. Jugador del juego de pelota sobre un fondo de serpientes, relieve en piedra, detalle de la estructura conocida como El Tzompantli. Chichén Itzá, Yucatán, cultura maya, Postclásico, in situ. Dibujo de Rubén Rosas.

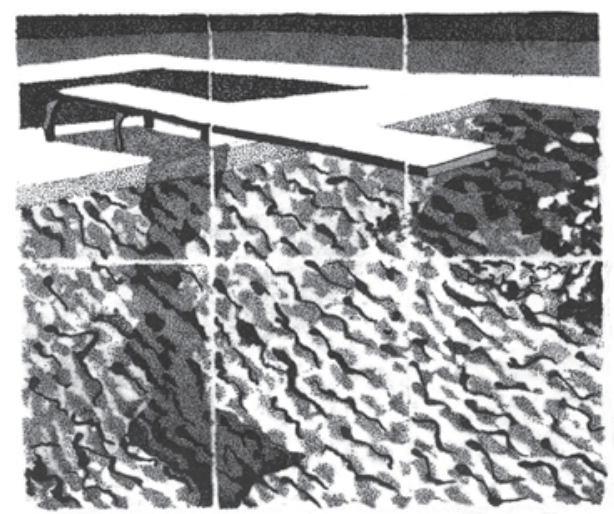

Figura 23. Serpientes de luz proyectadas sobre la superficie del agua. Pintura de David Hockney, de la serie "Paper Pools" (1978). Dibujo de Rubén Rosas, con base en la pintura de Hockney. 


\section{Conclusión}

Este ensayo partió de la suposición de que el ícono del jaguar reticulado participa de un lenguaje plástico que compartieron todas las culturas mesoamericanas, donde el jaguar representa, como se sabe gracias a innumerables mitos, al demiurgo por excelencia. Fue el amo y señor in illo tempore, el habitante invisible del caos precósmico, acuático y oscuro que antecedió al mundo ordenado y creado por los dioses para los hombres. La hipótesis consistía en que no se trataba de un animal, sino de una metáfora auditiva. Gracias a esta maravillosa metáfora se plasmó una relación interna de semejanza entre el rugir del felino y el rugir del cielo, en cuanto voz del trueno y verbo creador, lo cual inspiró la creación de la bestia, que así se convirtió en el verbo encarnado.

Sobre la base del caso específico del jaguar reticulado teotihuacano, cuyo cuerpo está conformado por una retícula de diseños entrelazados sinuosos y cuyo semblante terrible, al mirar de frente, está constituido a su vez por dos perfiles enfrentados, este ensayo emprendió un análisis hermenéutico comparativo, buscando íconos mesoamericanos con atributos parecidos para develar el contenido tras estas particularidades plásticas.

Primero se estableció que los perfiles que integran un solo rostro felino que mira de frente pertenecen a otra bestia que goza de la misma prominencia en el bestiario mesoamericano: la serpiente. Asimismo, se comprobó que esta cara trinitaria, constituida por dos cabezas de serpientes, que al juntar sus perfiles forman una sola cara de características felinas, existió en la iconografía desde el periodo preclásico olmeca, es decir, desde la aurora misma de las culturas mesoamericanas, hasta el posclásico. De modo que esta fiera fantástica atraviesa como un hilo rojo tres mil años de cultura mesoamericana, lapso en el cual se reconfiguró e innovó constantemente.

Más tarde se descubrió que tras el binomio serpiente-jaguar que preponderó en el arte de esas culturas se encuentra no sólo la metáfora del trueno, sino asimismo la metáfora del rayo luminoso, en cuanto metáfora visual del momento inaugural del cosmos. Momento en que, según los mitos cosmogenésicos, la luz de los rayos y relámpagos iluminaba esporádicamente la oscuridad de aquel tiempo anterior al tiempo. Instante en el que un fulgor luminoso, al detonar sobre el espejo 
de las aguas del océano primigenio, no sólo se refleja a manera de dos víboras encontradas, sino que, además, da origen sobre el espejo de las aguas al estertor del trueno. Habiendo encontrado así no sólo una, sino dos metáforas primigenias, la del rayo y la del trueno, tanto como su encarnación respectiva en una serpiente o, mejor dicho, en dos víboras enfrentadas a manera de un ente reflejante y su reflejo, se mostraron sus materializaciones como dos seres zoomorfos.

Después se reveló cómo estas culturas habían procedido al representar el contexto, en concreto, el espejo del agua. La representación de la superficie del agua, en sí invisible, a no ser que refleje la luz proyectada en ella, ha sido un reto en la plástica desde la antigüedad hasta nuestros días. Se pudo comprobar que el pintor inglés David Hockney, uno de cuyos temas predilectos ha sido la representación de la superficie del agua, encontró soluciones plásticas idénticas a las de los artistas prehispánicos. De esta manera se mostró que la intuición plástica, la ciencia del pintor, siendo universal, debe verse como el fundamento del desarrollo plástico en cuanto lenguaje. La plástica, uno de los lenguajes inventados por el hombre, debe sumarse al conocimiento de los mitos y demás fuentes primarias y secundarias, en la labor de descifrar la creación de las obras iconográficas de las altas culturas. O sea, aquello que ayudó a concebirlas también puede ayudar a develar su misterio.

Una vez realizado este recorrido hermenéutico, se restituyó el mensaje subyacente en los jaguares reticulados, en cuanto jaguares de agua que, carentes de corporeidad, están constituidos por la luz primigenia que dibujó en el espejo del agua redes luminosas. Al estallar el estruendo del trueno sobre la superficie iluminada por dos rayos, uno real y el otro virtual, el primero siendo el reflejante y el segundo el reflejo, se origina el momento augural del universo que antecede a la primera aurora, el primer día. Por último, se descubrió que del mismo modo en que la metáfora visual y auditiva del rayo y del trueno cosmogenésicos encontró en el dragón una representación objetivada, también el espacio caótico precósmico del océano de los orígenes encontró en la urbe mesoamericana una objetivación arquitectónica en la forma de las canchas del juego de pelota. Si éstas se entienden como espejos hierofánicos, nos permiten conceptualizar la representación ritual del encuentro de las dos fuerzas constituyentes del universo, el rayo y su 
reflejo, que liberan, tras herir la superficie del agua, al Sol, a la primera aurora del cosmos, al primer día de un mundo ordenado, contrapuesto al caos precósmico en que sigue habitando el monstruo que aguarda la llegada predestinada del Apocalipsis, a fin de devolver al mundo a la oscuridad primera.

La implementación del poder de la mirada plástica como herramienta de la iconología, me parece, puede enriquecer y complementar los estudios históricos, ayudando significativamente no sólo en el desciframiento del discurso plástico de la antigüedad, sino también en el develamiento del funcionamiento de las estructuras de poder en que la bestia se ha convertido en un símbolo emblemático del poder divino y real. Quizás estos íconos bestiales, más que hablarnos de los jaguares y las serpientes, mucho nos pueden decir sobre la conducta del hombre. Fue a partir del alumbramiento del espejo hierofánico que el hombre osó levantar sus ojos mortales "contra su condición y la creación entera", dominado por la desmesura de su sed de dominio y sumido siempre en un "tormentoso mar de desesperación fatal" (Eliade 1972: 197). Una y otra vez vemos en la mitología que los héroes civilizadores, hombres rebeldes por excelencia, empiezan y terminan su existencia entre "rayos y relámpagos" (Camus 2013: 48).

\section{Bibliografía}

Agamben, Giorgio y Monica Ferrando (2014). La muchacha indecible. Mito y misterio de Kore. Madrid, Sexto Piso.

Bonifaz Nuño, Rubén (1989). Hombres y serpientes, Iconografía olmeca. México, Universidad Nacional Autónoma de México.

CAmus, Albert (2013). El hombre rebelde. Madrid, Alianza.

Clark, John E. (2008). “Teogonía olmeca: perspectivas, problemas y propuestas", en María Teresa Uriarte y Rebecca B. González Lauck (eds.), Olmeca. Balance y perspectivas, Memoria de la primera Mesa Redonda. México, Instituto de Investigaciones Estéticas, Universidad Nacional Autónoma de México/Instituto Nacional de Antropología e Historia/Consejo Nacional para la Cultura y las Artes: 145-183.

Curiel Defossée, Fernando (dir.) (1993). El libro del Consejo (Popol Vuh). México, Universidad Nacional Autónoma de México/Programa Editorial.

Eliade, Mircea (1972). Tratado de historia de las religiones. México, Era. 
Fuente, Beatriz de la (coord.) (1995). La pintura mural prehispánica en México, I Teotihuacán, tomo II. México, Instituto de Investigaciones Estéticas, Universidad Nacional Autónoma de México.

GARZA, Mercedes de la (1998). Rostros de lo sagrado en el mundo maya, México, Paidós/Universidad Nacional Autónoma de México.

GonzÁlez Torres, Yolotl (2001). Animales y plantas en la cosmovisión mesoamericana. México, Consejo Nacional para la Cultura y las Artes/Instituto Nacional de Antropología e Historia.

Izzi, Massimo (2000). Diccionario ilustrado de los monstruos. Ángeles, diablos, sirenas y otras criaturas del imaginario. Barcelona, José J. de Olañeta.

Juanes, Jorge (2009). Leonardo da Vinci, Pintura y sabiduría hermética. México, Itaca.

Lecourt, Dominique (1982). Para una crítica de la epistemología. México, Siglo XXI.

LÉvy-Strauss, Claude (1968). Antropología estructural, Buenos Aires, Editorial Universitaria de Buenos Aires.

López-Austin, Alfredo (1994). Tamoanchan y Tlalocan. México, Fondo de Cultura Económica.

Lotman, Iuri M. (1966). La Semiósfera I. Semiotica de la cultura del texto, Madrid, Cátedra.

Matos Moctezuma, Eduardo (2016). “Personajes híbridos en Mesoamérica?”, Arqueología Mexicana, Tlaxcala, mayo-junio, núm. 139: 86-87.

MülLER, Heike (2016). El dios oculto, Hermenéutica del ícono de la serpiente de fuego-jaguar, una teoría de la metáfora, tesis de licenciatura en arqueología. México, Escuela Nacional de Antropología e Historia.

OliviER, Guilhem (2004). Tezcatlipoca. Burlas y metamorfosis de un dios azteca. México, Fondo de Cultura Económica.

El libro del consejo (Popol Vuh) (1993). Prólogo de Francisco Monterde; traducción y notas de Georges Raynaud, J. M. González de Mendoza y Miguel Ángel Asturias; introducción y notas de Maricela Ayala Falcón. México: Programa Editorial de la Coordinación de Humanidades (Biblioteca del Estudiante), Universidad Nacional Autónoma de México.

Ruiz Gallut, María Elena (2005). “Tras la huella del jaguar en Teotihuacán”, Arqueología Mexicana, El jaguar en el México prehispánico, vol. XII, núm. 72: 28-36.

SARTRE, Jean-Paul (1986). El ser y la nada, Ensayo de ontología fenomenológica. México, Alianza.

VAlverde Valdés, María del Carmen (2005). "El jaguar entre los mayas: entidad oscura y ambivalente", Arqueología Mexicana, El jaguar en el México Prehispánico, vol. XII, núm. 72: 46-51. 